\title{
Nudging out consumer welfare
}

Energy Econ. 86, 104616 (2020)

Choice defaults are a popular policy instrument because they are cheap to administer and do not infringe on freedom of choice: people are nudged toward a particular option, but are able to opt-out. In the energy context, green defaults increase consumer demand for renewable energy. However, it is not clear whether costs and benefits of such interventions are equally distributed. To understand the welfare implications of green energy defaults, Claus Ghesla from Pöyry Management Consulting and collaborators from ETH Zurich and Zurich University of Applied Sciences analysed how opt-out rates compare to active contract preferences across sociodemographic groups.

Residential consumers of a Swiss electricity utility that implemented a green choice default in 2013 were surveyed about their preferred electricity contract four years later. Of the $75 \%$ of surveyed households enrolled in the green default contract, $40 \%$ actually preferred a cheaper but less green contract, and $27 \%$ preferred a more expensive, more green contract. Importantly, those preferring a cheaper option tended to be of lower socio-economic status, whereas those preferring more expensive greener options were of higher socio-economic status. Thus, although a cost-benefit analysis based on annual consumption data for surveyed households and the carbon intensity and prices associated with the different contracts suggests that the green electricity default lowers emissions, it does so at a cost to poorer households who are more susceptible to default effects.

Jenn Richler

Published online: 19 February 2020

https://doi.org/10.1038/s41560-020-0570-4 